Recently, Bhattacharyya and colleagues ${ }^{4}$ reported a case of decompression of an emphysematous bulla through a transbronchial aspiration needle. We considered this strategy to be unsuitable for our case because of the high risk of pneumothorax or bronchopleural fistula.

Finally, we considered using EBVs, which were designed for the treatment of emphysema and have been applied successfully for occlusion of bronchopleural ${ }^{1}$ and bronchocutaneous $^{5}$ fistulas. The EBVs work like a Heimlich valve, allowing escape of air and secretions from bulla at expiration (Figure 2,B) but preventing air inflow at inspiration (Figure $2, C$ ), thus resulting in a redirection of airflow away from the blocked segments. The result is deflation of the GEB and the re-expansion of the more normal adjacent lung.

Our experience confirms that this noninvasive bronchoscopic treatment may represent a valuable alternative for patients who are poor surgical candidates. Bronchoscopic
EBV insertion is easily placed by a thoracic surgeon familiar with interventional endoscopic procedures, well tolerated, and easily removed if necessary. Large series and longterm trials are needed for adequate validation of the technique described.

\section{References}

1. Anile M, Venuta F, De Giacomo T, Rendina EA, Diso D, Pugliese F, et al. Treatment of persistent air leakage with endobronchial one-way valves. J Thorac Cardiovasc Surg. 2006;132:711-2.

2. Gordon LS. Reduction pneumoplasty for giant bullous emphysema. Chest. 1996; 109:540-8.

3. Macarthur AM, Fountain SW. Intracavity suction and drainage in the treatment of emphysematous bullae. Thorax. 1977;32:668-72.

4. Bhattacharyya P, Sarkar D, Nag S, Ghosh S, Roychoudhury S. Transbronchial decompression of emphysematous bullae: a new therapeutic approach. Eur Respir J. 2007;29:1003-6.

5. Snell GI, Holsworth L, Fowler S, Eriksson L, Reed A, Daniels FJ, et al. Occlusion of a broncho-cutaneous fistula with endobronchial one-way valves. Ann Thorac Surg. 2005;80:1930-2.

\title{
Right ventricular outflow tract reconstruction using a valved femoral vein homograft
}

\author{
Pranava Sinha, MD, Sachin Talwar, MCh, Achintya Moulick, MD, and Richard Jonas, MD, Washington, DC
}

Restoration of right ventricle to pulmonary artery continuity in infancy and early childhood may require a conduit. However, appropriately sized pulmonary and aortic homografts in the range of 10 to $16 \mathrm{~mm}$ in diameter are frequently not available. Furthermore, pulmonary and aortic homografts are prone to early calcification, especially of the subvalvar muscle. They also require a hood of supplementary tissue, such as pericardium for the proximal anastomosis. We report our recent experience with the use of an alternative homograft that avoids many of these problems, namely, a valved segment of cryopreserved femoral vein homograft.

\section{CLINICAL SUMMARY}

Tetralogy of Fallot with pulmonary atresia was diagnosed in a 2-month-old girl weighing $5.7 \mathrm{~kg}$, and she was scheduled for elective primary repair. Her central pulmonary ar-

From the Department of Cardiovascular Surgery, Children's National Medical Center, Washington, DC.

Received for publication Sept 2, 2008; accepted for publication Oct 10, 2008; available ahead of print Dec 22, 2008.

Address for reprints: Richard A. Jonas, MD, Chief of Cardiovascular Surgery, Children's National Medical Center, 111 Michigan Avenue, NW, Washington, DC 20010 (E-mail: rjonas@cnmc.org).

J Thorac Cardiovasc Surg 2010;139:226-8

$0022-5223 / \$ 36.00$

Copyright (c) 2010 by The American Association for Thoracic Surgery doi:10.1016/j.jtcvs.2008.10.018 teries were $3 \mathrm{~mm}$ in size. Because of the long-segment pulmonary atresia, interposition of a conduit was necessary; however, an appropriately sized aortic or pulmonary homograft (11-12 mm) was not available. After standard hypothermic cardiopulmonary bypass was established and cardioplegic arrest was achieved, a right ventriculotomy was made and the ventricular septal defect was closed in standard fashion. A 3-mm fenestration was made in the ventricular septal defect patch because of the small size of the pulmonary arteries and incomplete arborization in anticipation of high postoperative right ventricular pressure. An adult cryopreserved femoral vein homograft with diameter tapering from 16 to $11 \mathrm{~mm}$ (Cryolife Inc, Kensaw, GA) was chosen, thawed, and rinsed. The homograft was gently distended with the rinse solution, and a segment 11 to $12 \mathrm{~mm}$ in diameter and $4 \mathrm{~cm}$ in length containing a competent valve (Figure 1) was identified and cut from the $30 \mathrm{~cm}$ of vein available. By taking care to maintain the appropriate direction of flow through the graft, the distal anastomosis to the pulmonary artery was fashioned using continuous 6-0 polypropylene suture. After this, the proximal end of the graft was beveled and anastomosed to the right ventriculotomy using a running 5-0 polypropylene suture. No pericardial hood was necessary.

After the reconstruction, the patient was weaned easily from cardiopulmonary bypass and made an uneventful 

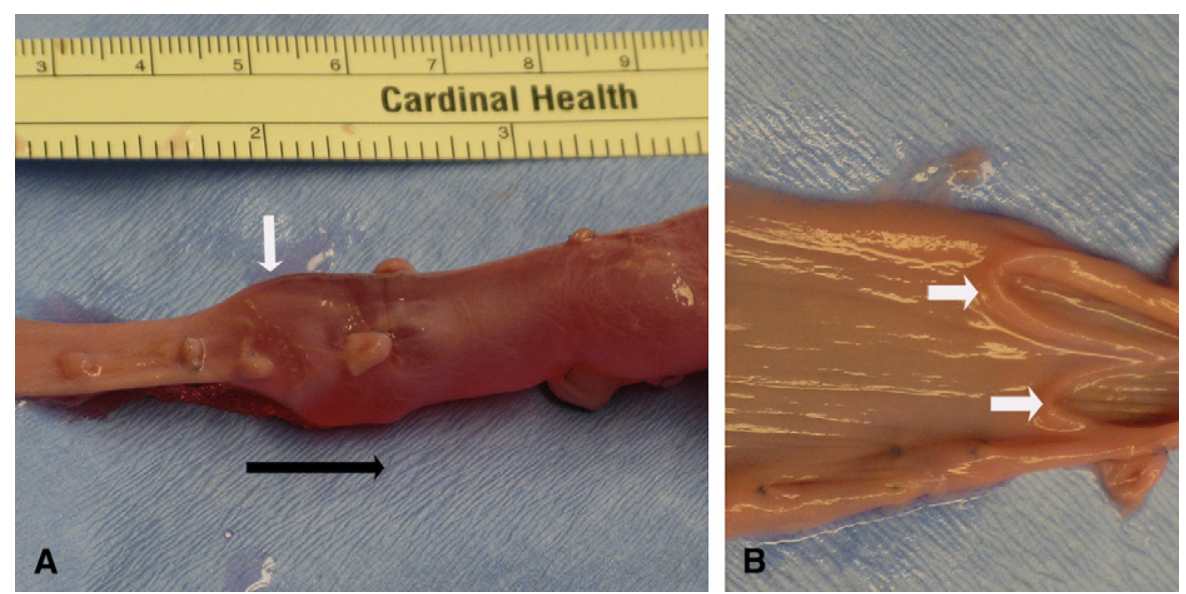

FIGURE 1. Distended femoral vein homograft (A) showing competent valve (white arrow) (direction of flow, black arrow) (B) and filleted to demonstrated valves (white arrows).

postoperative recovery. Predischarge transthoracic echocardiogram revealed laminar flow through the conduit without any regurgitation or gradient across the valved homograft (Figure 2, $A$ and $B$ ).

\section{DISCUSSION}

The search for an ideal homograft for right ventricular outflow tract reconstruction continues. An ideal conduit should be competent, be free of gradients, be resistant to calcification, not degenerate rapidly, be available in all sizes, and be inexpensive. Unfortunately, no such conduit is available. Pulmonary homografts have been the preferred conduits because of more rapid calcification of aortic homografts in this position in younger patients. ${ }^{1,2}$ However, appropriately sized pulmonary homografts for neonates and infants are not easily available, and early conduit failures are common with smaller sized pulmonary homografts. ${ }^{3}$ When larger sized homografts are used, delayed sternal closure may be needed to avoid significant conduit compression and hemodynamic compromise in the early postoperative phase, which adds significantly to the morbidity. An alternative approach consists of downsizing large-sized homografts ${ }^{4,5}$ but adds to the operating time, and pulmonary regurgitation may occur. ${ }^{6}$ The thick arterial wall of large homografts is often unsuitable for anastomosis to fragile hypoplastic pulmonary arteries. Bovine internal jugular vein grafts (Contegra, Medtronic Inc, Minneapolis, Minn) have also been used ${ }^{7}$ but are glutaraldehyde preserved and more prone to accelerated calcification and degeneration, and may make the reoperation difficult.

Cryopreserved femoral vein homografts (Cryolife Inc) are marketed as segments 25 to $30 \mathrm{~cm}$ in length that taper from $10 \mathrm{~mm}$ at the inflow end to approximately 15 to $16 \mathrm{~mm}$ at the other end. On average, there are 2 to 3 valves. Therefore, it is almost always possible to obtain a valved segment of the desired size for smaller patients. The femoral vein is thin walled compared with the aortic or pulmonary homograft and is appropriate for anastomosing to small thin-walled pulmonary arteries. Absence of thick subvalvar muscle and
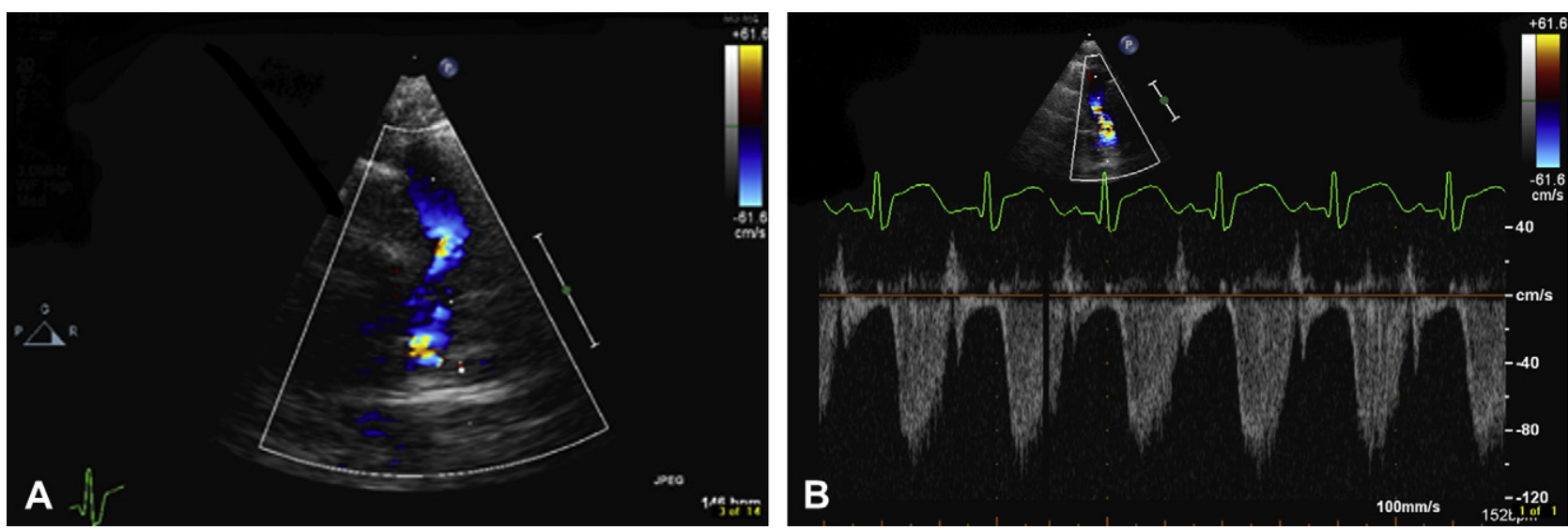

FIGURE 2. Parasternal short-axis view of right ventricular outflow tract showing laminar flow through the reconstructed right ventricular outflow tract (A) and absence of any pressure gradient across the conduit (B). 
glutaraldehyde treatment may allow longer freedom from calcification. In addition, the vein homograft is significantly less expensive than valved pulmonary or aortic homografts.

\section{CONCLUSIONS}

Although no long-term information is available regarding performance of vein homografts in the application described, they have been used as alternative arterial conduits in infrainguinal vascular surgery ${ }^{8}$ with acceptable short-term results. Thus, we are encouraged to explore the suitability of these conduits in a pediatric application.

\section{References}

1. Clarke DR, Campbell DN, Hayward AR, Bishop DA. Degeneration of aortic valve allografts in young recipients. J Thorac Cardiovasc Surg. 1993;105:934-41.
2. Santini F, Piccin C, Prioli A, Pessotto R, Mazzucco A. Accelerated aortic allograft fibrocalcification after right ventricular outflow tract reconstruction in pediatric patients: report of two cases. Eur J Cardiothorac Surg. 1996;10: 290-3.

3. Schreiber C, Sassen S, Kostolny M, Horer J, Cleuziou J, Wottke M, et al. Early graft failure of small-sized porcine-valved conduits in reconstruction of the right ventricular outflow tract. Ann Thorac Surg. 2006;82:179-85.

4. Michler RE, Chen JM, Quaegebeur JM. Novel technique for extending the use of allografts in cardiac operations. Ann Thorac Surg. 1994;57:83-7.

5. McMullan DM, Oppido G, Alphonso N, Cochrane AD, d'Acoz YdU Brizard CP. Evaluation of downsized homograft conduits for right ventricle-to-pulmonary artery reconstruction. J Thorac Cardiovasc Surg. 2006;132:66-71.

6. Hiramatsu T, Miura T, Forbess JM, Brizard C, Jonas RA. Downsizing of valve allografts for use as right heart conduits. Ann Thorac Surg. 1994;58:339-42.

7. Sierra J, Christenson JT, Lahlaidi NH, Beghetti M, Kalangos A. Right ventricular outflow tract reconstruction: what conduit to use? Homograft or Contegra? Ann Thorac Surg. 2007;84:606-11.

8. Dosluoglu HH, Kittredge J, Cherr GS. Use of cryopreserved femoral vein for in situ replacement of infected femorofemoral prosthetic artery bypass. Vasc Endovascular Surg. 2008;42:74-8. 